\title{
Shade response of a full size TESSERA module
}

Lenneke H. Slooff ${ }^{1 *}$, Anna J. Carr ${ }^{1}$, Koen de Groot ${ }^{1}$, Mark J. Jansen ${ }^{1}$, Lars Okel ${ }^{1}$, Rudi Jonkman ${ }^{2}$, Jan Bakker ${ }^{3}$, Bart de Gier ${ }^{3}$, and Adriaan Harthoorn ${ }^{4}$

${ }^{1}$ Energy Research Centre of the Netherlands, P. O. Box 1, 1755 ZG Petten, The Netherlands

${ }^{2}$ Heliox, De Waal 24, 5684 PH Best, The Netherlands

${ }^{3}$ Eurotron, Van Beukelaarweg 4, 2971 VL Bleskensgraaf, The Netherlands

${ }^{4}$ Stafier, P. O. Box 34, 6900 AA Zevenaar, The Netherlands

*E-mail: slooff@ecn.nl

Received February 10, 2017; revised March 30, 2017; accepted April 2, 2017; published online July 4, 2017

A full size TESSERA shade tolerant module has been made and was tested under various shadow conditions. The results show that the dedicated electrical interconnection of cells result in an almost linear response under shading. Furthermore, the voltage at maximum power point is almost independent of the shadow. This decreases the demand on the voltage range of the inverter. The increased shadow linearity results in a calculated increase in annual yield of about 4\% for a typical Dutch house. (C) 2017 The Japan Society of Applied Physics

\section{Introduction}

Under partial shading of photovoltaic (PV) modules, power from non-shaded cells is dissipated in the shaded cell, resulting in an increase in the cell temperature. ${ }^{1,2)}$ These so-called hotspots reduce the performance of the module and in some cases, can cause irreversible failure of the module as the temperature becomes so high that delamination or fire occurs. To circumvent these problems, standard PV modules contain bypass diodes that come into action when cells are shaded. ${ }^{3-5)}$ Normally a series of 20 cells is connected to one bypass diode. So a 60 -cell module will have 3 bypass diodes. The negative aspect of this approach is that these modules have a significantly lower output under partial shading conditions. A shadow of $10 \%$ on a module can decrease the output by $30 \% .^{6,7)}$ As a result, modules are often only placed at the most sunny positions on buildings [see Figs. 1(a) and 1(c)], where shading will have a minimal effect. This not only results in a much less aesthetic roof coverage, but also hinders application in the built environment, as owners decide not to install this less aesthetic option. If a full roof coverage as in Figs. 1(b) and 1(d) could be possible without major losses in power output, this could speed up the implementation and acceptance of PV.

The current state-of-the-art to tackle this problem is either by adding electronics to the system (power optimizers or micro-inverters), ${ }^{8-14)}$ or by re-designing the cells such that they have a softer breakdown characteristics, ${ }^{15-21)}$ to make modules less sensitive to shade. ${ }^{22)}$ The first solution has led to significantly better output under shading conditions, but still needs to prove itself in terms of cost and reliability. ${ }^{23)}$ Adaptation of the module design has led to increased manufacturing complexity or reliability issues.

In this paper we report on the TESSERA concept ${ }^{24,25)}$ which is based on existing back contact technology $y^{26-28)}$ and is inherently more shade tolerant. In the back contact technology all contacts to the cell are placed on the rear of the cell. Cells are placed on a conductive back sheet using conductive adhesive. The interconnection between the cells is established via the conductive adhesive and the conductive
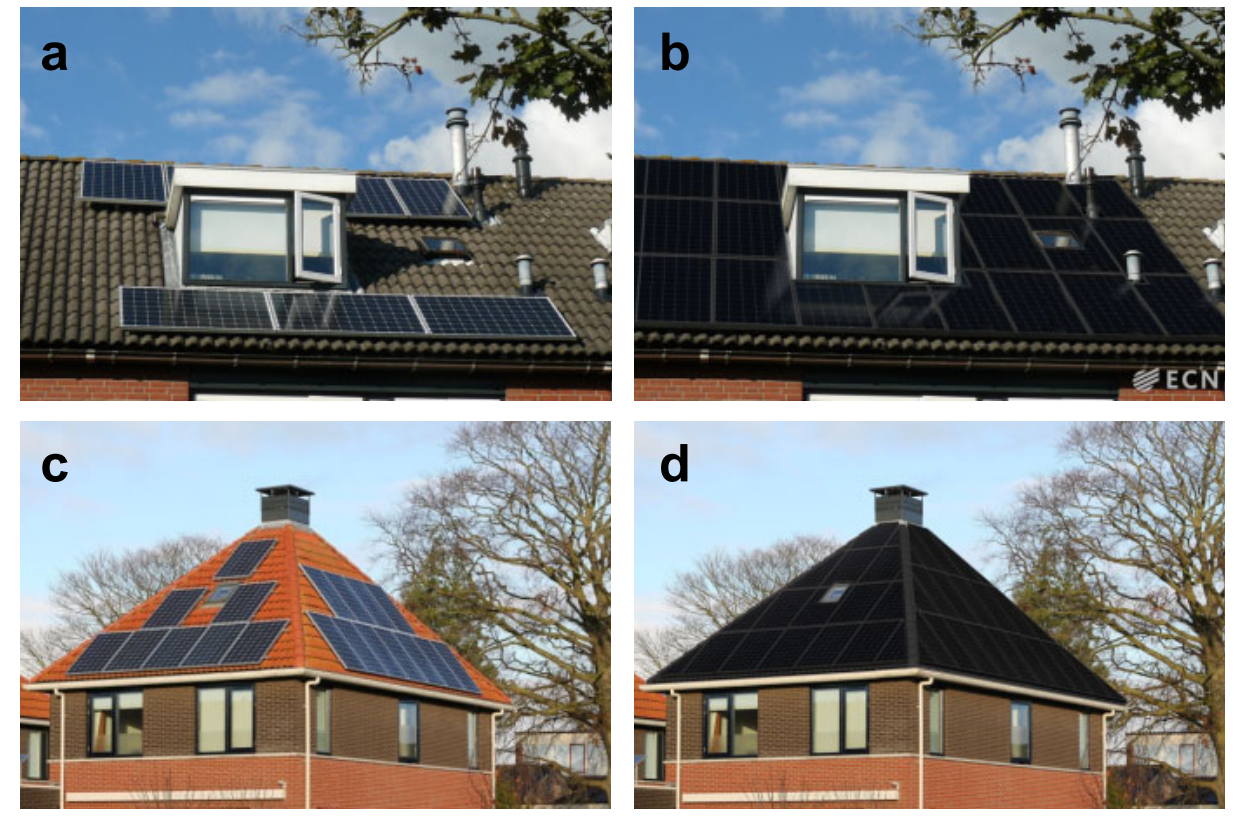

Fig. 1. (Color online) State of the art situation for PV on rooftops (a, c). Application of full roof coverage using shade tolerant modules (b, d). 


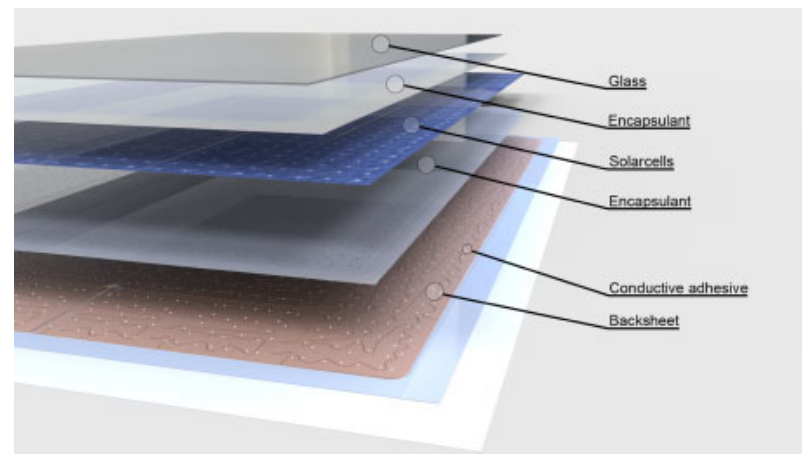

Fig. 2. (Color online) Illustrations of the back contact foil technology.

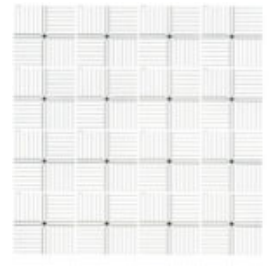

6 inch MWT cell

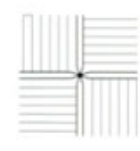

SubCell

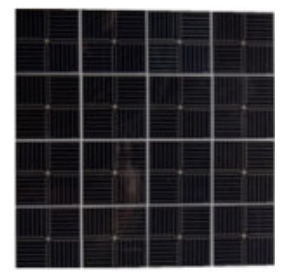

SubCell Group (SCG)
Fig. 3. (Color online) Building a TESSERA module: a 6 in. MWT cell with 16 vias is cut into 16 subcells; the subcells are placed in block of 16 , the SCG, with $1 \mathrm{~mm}$ spacing between the cells; the cells in SCG are connected in series to a small bypass diode.

back sheet (see Fig. 2). This concept allows for easy changing of the cell interconnection pattern as well as size and shape of the module.

In the TESSERA concept, the back contact cell ${ }^{29,30)}$ is cut in smaller pieces and placed in series, thereby reducing the current and increasing the voltage. The same manufacturing equipment as for standard back contact modules can be used, with a small adaptation to the manufacturing line. Hence, the modules can be manufactured without adding manufacturing complexity. The linear shading response is achieved by optimizing the electrical interconnection of the cells. Because of the different PV module output, a dedicated inverter is required. However, this inverter can be much simpler than a standard one, as the operating voltage is almost independent of the shade fraction.

\section{Module design}

Most PV modules today consist of 3 strings, with 20 cells connected in series in the string. The string is protected by a bypass diode. When one cell is shaded by more than $15 \%$, the current of the string is bypassed through the diode and the string output is lost. Hence, one shaded cell can cause $1 / 3$ of the module output to be lost. In other words, the module consists of 3 "pixels".

This can be improved by increasing the number of pixels. For example, by combining fewer cells to one diode. Solar cells have a high current (7.5-9 A), so diodes which can carry this current would need to be placed at various positions in the module. This is difficult and expensive.

A better solution is to divide the 6 in. cells in 16 smaller subcells (Fig. 3), with a lower current (the current scales linearly with the cell area). A group of subcells (SCG, here 16 cells) can then be connected in series to a smaller in- a

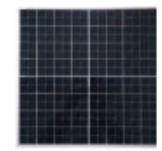

b

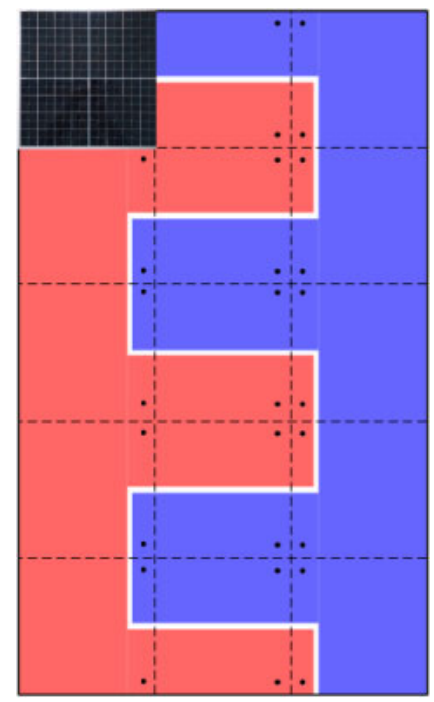

Fig. 4. (Color online) (a) Group of four SCGs make a MBB. (b) 15 MBBs make up a full size module. The red and blue color show the different polarities.

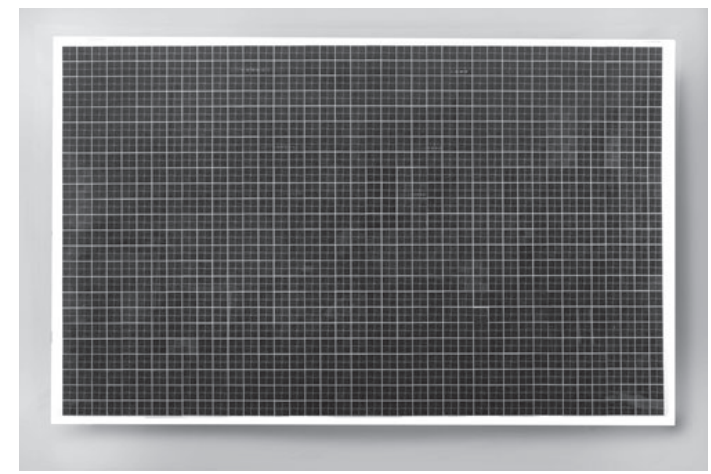

Fig. 5. Full size TESSERA module.

laminate diode. Four of these SCGs are subsequently connected in series into a module building block (MBB). The module interconnection wiring is based on a single layer of conductor foil. The conductor foil is divided in a positive and negative section by an isolation trench in such a way that every unit module has access to the local positive and negative section. The resulting module consists of $15 \mathrm{MBB}$ 's in parallel, each containing 64 series connected SubCells (see Fig. 4). The resulting full size module is shown in Fig. 5. In this first test of the TESSERA module, no diodes were present, but all other electrical connections are as described above. Future TESSERA modules will include the diodes.

\section{Results and discussion}

Shadow experiments were performed in a PASAN flash tester on a TESSERA module and a standard 3 string module, $\mathrm{H}$-pattern full square multi crystalline 60 cell module made by GPPV (GPM230P-B-60). In the experiment up to 12 SCGs were fully shaded. Figure 6 shows the shaded areas and the corresponding current-voltage $(I-V)$ curves of both modules. The standard module was measured with diodes, the TESSERA without diodes. To make a fair comparison we have included calculated results based on an LTSpice model for the TESSERA module with and without diodes. The calculated results for the TESSERA module without diodes 

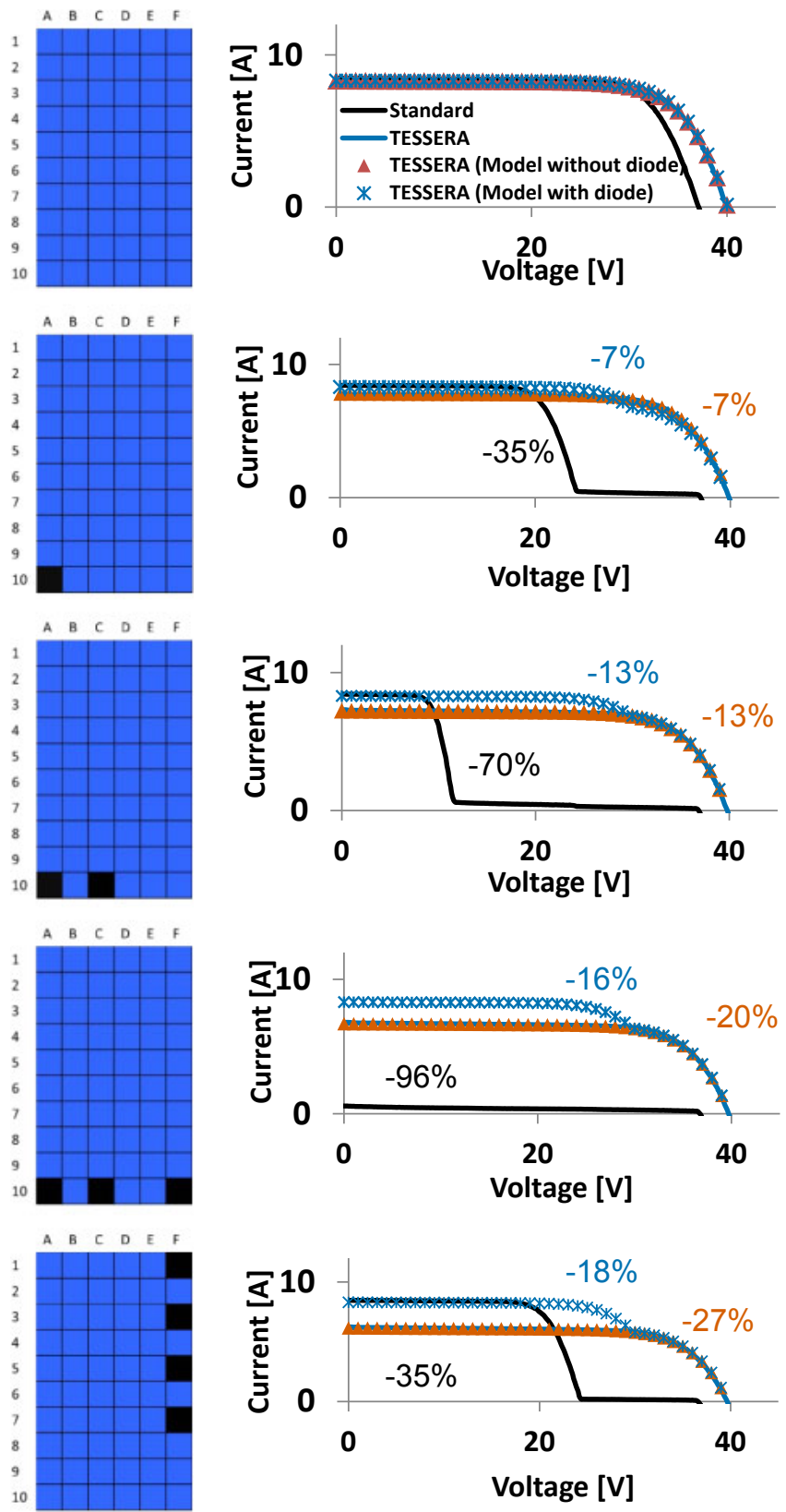

Fig. 6. (Color online) Illustration of the shaded areas during $I-V$ measurements on the left and the corresponding $I-V$ graphs of a TESSERA and standard module on the right. The numbers in black give the measured power loss for the standard module, in blue the measured and calculated numbers for the TESSRA module without diodes and in red for the TESSERA module with diodes.

overlap extremely well with the measured results, giving confidence that the model is capable of describing the TESSERA module. For the situation with diodes, the TESSERA module still shows much less power loss upon shading compared to the standard module. The same data is plotted in Fig. 7 as power at maximum power voltage versus the applied voltage. Here the difference between the standard module and the TESSERA becomes more pronounced. Where the power of the TESSERA only drops slightly, the power of the standard modules decreases substantially, and when all strings are affected, almost completely vanishes.

Figure 8 shows the power at maximum power point of these and additional measurements for the TESSERA module without diodes. As can be seen the power output drops
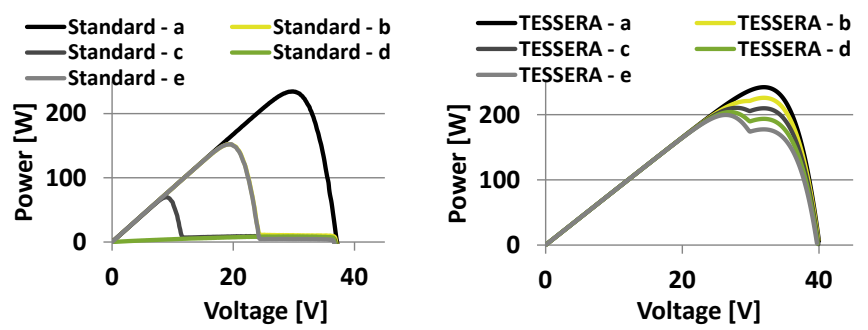

Fig. 7. (Color online) Power vs voltage curves for the Standard and TESSERA module, showing the effect of the different shades. These curves correspond to the $I-V$ curves and shading in Fig. 6 with the following codes: (a) no shade, (b) A10, (c) A10+C10, (d) A10+C10+F10, and (e) F1+F3+ F5+F7.

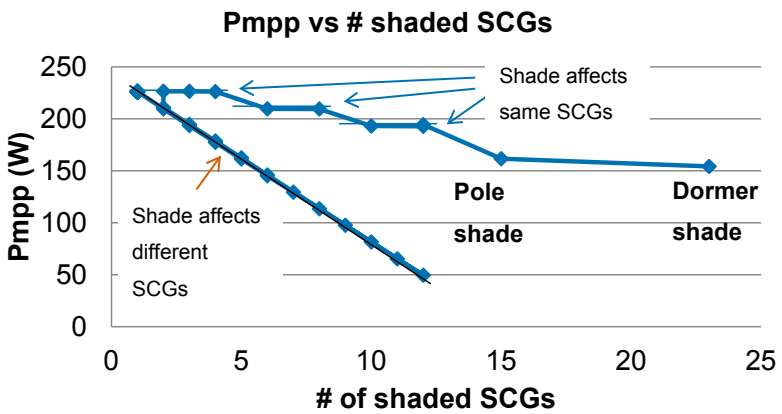

Fig. 8. (Color online) Power output at maximum power point versus the number of shaded SCGs (i.e., per number of 16 cells).

linearly with the number of shaded SCGs, but two lines can be observed. The top line is the drop in power when each additional shaded SCG is first filling one MBB before the next $\mathrm{MBB}$ is affected. In that case a step-wise dependence is seen, where the power drops per four SCGs. The blue horizontal lines indicate these steps. The other line is for the situation where each additional SCG is part of a new MBB. In that case the power drops faster. Also shown are the results for a dormer- and pole-type of shade of which the setup and resulting $I-V$ curves are shown in Fig. 9.

The dormer and pole shades affect multiple SCGs and MMBs. Still the module delivers a substantial output power. The data of Fig. 8 is also plotted as a function of the number of shaded MBBs (see Fig. 10) and shaded area (Fig. 11).

Figure 10 shows that the power drop is linear with the number of MBBs that are shaded. The power loss versus shaded module area in Fig. 11 shows, as expected, the same two lines as the power versus the number of SCGs. It shows that the TESSERA concept is very shadow tolerant, especially for compact shades (top lines), i.e., shadows that affect adjacent cells and are not distributed patch-wise over the module. Also shown is the power loss as measured for a standard three-string module. As can be seen, the power drop for TESSERA is substantially less than for standard threestring modules.

The corresponding measured voltage of the TESSERA module at maximum power point does not vary significantly with increased shadow (see Fig. 12). Although the voltages will drop slightly when diodes are implemented (see Fig. 7), the voltage range at maximum power point is still much more narrow than for the standard module. All these measurements were performed without a micro-inverter. With microinverter, the overall output will reduce slightly for both the 

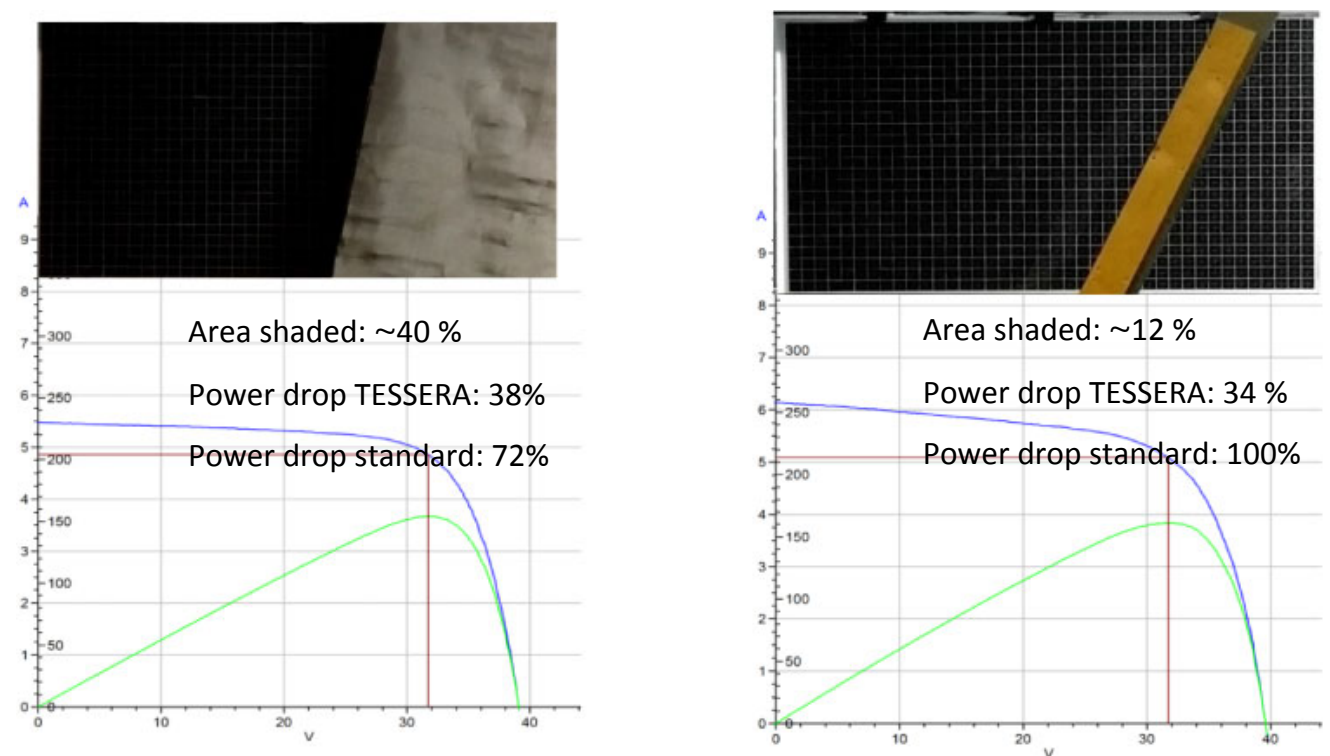

Fig. 9. (Color online) Measured indoor shading response of a full size TESSERA module.

Pmpp vs \# shaded MBB

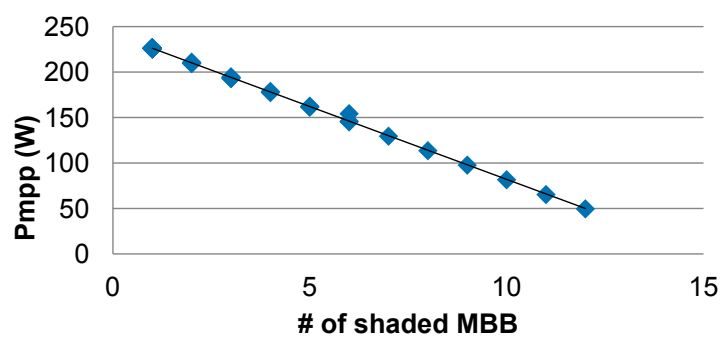

Fig. 10. (Color online) Power output at maximum power point versus the number of shaded MBBs.

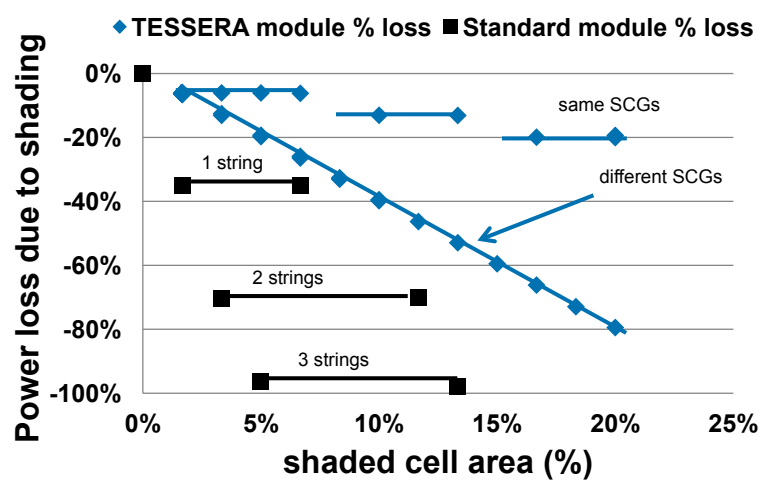

Fig. 11. (Color online) Power output at maximum power point versus the shaded module area. The black lines indicate the situation where the shade affects one, two, or three strings of the standard module.

TESSERA and the standard module as the efficiency of the micro-inverter is approximately $95 \%$. This will be similar for both module types. The fact that the voltage at maximum power point (MPP) in the TESSERA concept is rather independent of the shading has two advantages: 1) The MPP tracking of the micro-inverter can sample around a specific voltage to find the global maximum, and is thus insensitive to getting trapped in a local maximum as is the case with a standard module; 2) The voltage at MPP will be well above the voltage threshold of the micro-inverter, thereby allowing

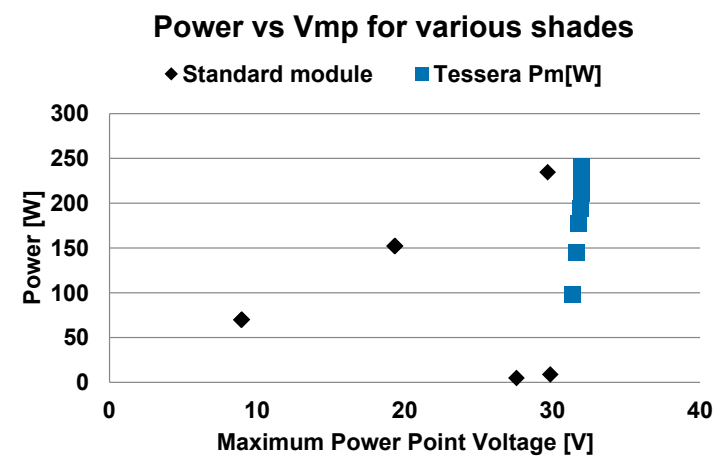

Fig. 12. (Color online) Measured power at maximum power point versus the voltage at maximum power point.

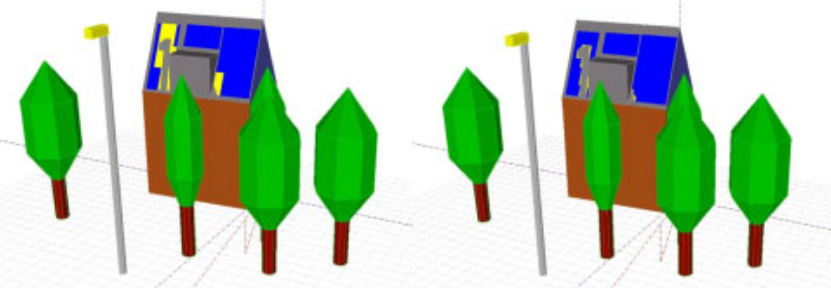

Fig. 13. (Color online) Schematic view of the lay-out used for the yearly yield calculations. Left for standard PV modules and right TESSERA. Reprinted with permission from Ref. 25. @ 2015 IEEE.

the inverter to work at all shading situations, whereas for the standard module under severe shadowing, the activation of the bypass diodes can make the voltage drop below the voltage threshold of the micro-inverter.

The TESSERA module, including diodes and a microinverter, have been modelled in the software program PVSyst. Figure 13 shows the modules on a typical Dutch building. The lamp in front of the house and the dormer create varying shadows on the panels. The effect of the shadows is calculated and compared to a standard three-string module. The results show that on January 11 between 11 and 12 AM, a standard module, also integrated with micro- 
inverters, has a loss of $32 \%$ due do the shadow of the dormer and lamp, whereas the TESSERA module loses only $17 \%$. So a gain of $24 \%$ in power with respect to a standard module. On a yearly basis the gain of a TESSERA module would be at least $4 \%$, in this particular system.

\section{Conclusions}

A first full size TESSERA shade tolerant module has been manufactured and shade measurements have been performed, showing the excellent shade tolerance of the concept. Polelike shading, that would reduce the output power of standard modules by almost $100 \%$, gives a reduction of only $34 \%$ for the TESSERA modules. This improved shade tolerance results in a gain in annual energy yield of at least $4 \%$ for a typical Dutch house.

\section{Acknowledgment}

This work is partly financed through the INHYPE project with financing from the Dutch Ministry of Economic Affairs (TKI Solar Energy, File No. TEZ0114002).

1) M. Simon and E. L. Meyer, Sol. Energy Mater. Sol. Cells 94, 106 (2010)

2) H. J. Solheim, H. G. Fjær, E. A. Sørheim, and S. E. Foss, Energy Procedia 38, 183 (2013).

3) S. Silvestre, A. Boronat, and A. Chouder, Appl. Energy 86, 1632 (2009).

4) R. Ramabadran and B. Mathur, 2nd Int. Conf. Emerging Trends in Engineering and Technology, 2009, p. 85.

5) E. Díaz-Dorado, A. Suárez-García, C. Carrillo, and J. Cidrás, Int. Symp. Power Electronics Electrical Drives Automation and Motion (SPEEDAM), 2010, p. 134.

6) A. S. Masoum, F. Padovan, and M. A. S. Masoum, Proc. IEEE Power and Energy Society Gen. Meet., 2010, p. 1.

7) H. Patel and V. Agarwal, IEEE Trans. Energy. Convers. 23, 302 (2008).

8) S. Poshtkouhi, V. Palaniappan, M. Fard, and O. Trescases, IEEE Trans. Power Electron. 27, 4656 (2012).

9) L. Rubin and F. F. Ordubadi, Patent ZA2011009387A (2012).

10) K. Sinapis, G. Litjens, M. van den Donker, W. Folkerts, and W. G. J. H. M van Sark, Energy Sci. Eng. 3, 510 (2015).

11) K. Sinapis, C. Tzikas, G. B. M. A. Litjens, M. N. van den Donker, W. Folkerts, W. G. J. H. M. van Sark, and A. Smets, 31st EUPVSEC, 2015, p. 1587.
12) K. Sinapis, T. T. H. Rooijakkers, C. Tzikas, G. B. M. A. Litjens, M. N. van den Donker, W. Folkerts, and W. G. J. H. M. van Sark, 32nd EUPVSEC, 2016, p. 2011.

13) A. Woyte, J. Nijs, and R. Belmans, Sol. Energy 74, 217 (2003).

14) A. J. Hanson, C. A. Deline, S. M. MacAlpine, J. T. Staruth, and C. R. Sullivan, IEEE J. Photovoltaics 4, 1618 (2014).

15) D. Rose and S. Daroczi, 20th EUPVSEC, 2005, p. 2670.

16) J. R. Kukulka, US Patent US5616185A (1997).

17) D. D. Smith, P. J. Cousins, A. Masad, A. Waldhauer, S. Westerberg, M. Johnson, X. Tu, T. Dennis, G. Harley, G. Solomon, S. Rim, M. Shepherd, S. Harrington, M. Defensor, A. Leygo, P. Tomada, J. Wu, T. Pass, L. Ann, L. Smith, N. Bergstrom, C. Nicdao, P. Tipones, and D. Vicente, IEEE PVSC, 2012, 001594.

18) A. Halm, B. de Gier, A. Schneider, V. D. Mihailetchi, L. J. Koduvelikulathu, G. Galbiati, H. Chu, R. Roescu, J. Libal, N. van Ommen, and R. Kopecek, 32nd EUPVSEC, 2016, p. 53.

19) I. Cesar, N. Guillevin, A. R. Burgers, A. A. Mewe, E. E. Bende, V. Rosca, B. B. Van Aken, M. Koppes, J. Anker, L. J. Geerligs, and A. W. Weeber, 29th EUPVSEC, 2014, p. 681.

20) R. Müller, C. Reichel, J. Schrof, M. Padilla, M. Selinger, I. Geisemeyer, J. Benick, and M. Hermle, Sol. Energy Mater. Sol. Cells 142, 54 (2015).

21) H. Chu, L. J. Koduvelikulathu, V. D. Mihailetchi, G. Galbiati, A. Halm, and R. Kopecek, Energy Procedia 77, 29 (2015).

22) H. Chu, A. Halm, V. D. Mihailetchi, G. Galbiati, and R. Kopecek, Energy Procedia 92, 540 (2016).

23) M. N. van den Donker, G. Verberne, K. Sinapis, and W. Folkerts, 32nd EUPVSEC, 2016, p. 1651

24) W. Eerenstein, M. J. Jansen, K. M. de Groot, A. J. Carr, L. A. G. Okel, M. J. J. A. Goris, J. A. M. van Roosmalen, E. E. Bende, R. Jonkman, R. van der Sanden, J. Bakker, B. de Gier, and A. Harthoorn, 30th EUPVSEC, 2015 , p. 477

25) A. J. Carr, K. de Groot, M. J. Jansen, E. Bende, J. van Roosmalen, L. Okel, W. Eerenstein, R. Jonkman, R. van der Sanden, J. Bakker, B. de Gier, and A. Harthoorn, 42nd IEEE PVSC, 2015, p. 1.

26) V. Rosca, M. J. A. A. Goris, L. A. G. Okel, B. B. Van Aken, N. Guillevin, A. A. Mewe, I. Cesar, and L. J. Geerligs, 31st EUPVSEC, 2015, p. 2545.

27) K. M. Broek, I. J. Bennett, M. J. H. Kloos, and W. Eerenstein, Energy Procedia 67, 175 (2015).

28) L. Hongfeng, Q. Zhe, C. Kaiyin, Z. Liyan, C. Xianzhi, L. Wei, G. Beaucarne, W. Peng, B. Chislea, Y. Yanghai, A. Zambova, K. M. Broek, I. J. Bennett, J. Bakker, N. van Ommen, and E. Frederikze, Photovoltaics Int. (PV-Tech), 23 (2014).

29) M. W. P. E. Lamers, C. Tjengdrawira, M. Koppes, I. J. Bennett, T. P. Visser, E. Kossen, B. Brockholz, A. A. Mewe, I. G. Romijn, E. Sauar, L. Camel, S. Julsrud, T. Naas, P. C. de Jong, and A. W. Weeber, Prog. Photovoltaics 20, 62 (2012).

30) W. Eerenstein, I. Bennett, D. Veldman, T. P. Visser, B. Brockholz, P. C. de Jong, C. A. Copetti, and P. Wijnen, 25th EUPVSEC, 2010, p. 3854. 